\title{
REFLEXÕES SOBRE A FACE OBSCURA DO PRECONCEITO E VIOLÊNCIA NA ESCOLA
}

\author{
REFLECTIONS ON THE OBSCURE FACE OF THE PREJUDICE AND VIOLENCE \\ IN THE SCHOOL
}

Cândida Alayde de Carvalho Bittencourt ${ }^{1}$

\begin{abstract}
Resumo
Discutir a relação entre o preconceito racial e a educação a partir de estudos sobre o preconceito racial na escola, procurando identificar os elementos intrínsecos ao preconceito, presentes nas relações sociais e nas instituições educativas e como eles se constituem na atualidade é uma necessidade premente. A escola, em relação as questões raciais, apresenta ambiguidades, pois, de um lado é vista como um caminho no processo de mobilidade social, e por outro é espaço de relações inter-raciais desfavoráveis para as crianças negras. Entendendo que numa sociedade de classes que produz e reproduz diferenças, o debate acerca de uma educação inclusiva fomenta questões significativas para se pensar a formação cultural e social brasileira, assim como a estrutura educacional que pode criar e recriar relações de discriminação e de preconceito. Dessa forma, é necessário um olhar crítico para desvelar a forma como as práticas permeadas de preconceito e pensamento preconceituoso são construídas no espaço escolar, pois a escola é uma instituição constantemente desafiada por práticas que produzem e reproduzem os conflitos sociais, evidenciando preconceitos, dominação, alienação, intolerâncias e racismos. Para romper esse ciclo é necessário, segundo Horkheimer e Adorno (1985), livrar os homens, das trevas da ignorância e possibilitar a compreensão da sociedade e da cultura, exercendo prática pedagógica crítica que contribua para a transformação social, o esclarecimento e a emancipação.
\end{abstract}

Palavras-chave: Educação; Preconceito; Violência

\begin{abstract}
To think the relation between the racial prejudice and the education from studies about the racial prejudice in the school, trying to identify the intrinsic elements to the prejudice, presents in the social relations and in the educative institutions and since they are the present is a pressing necessity. The school, in relation the racial questions, presents ambiguities, so, from a side is seen how a way in the process of social mobility, and for other it is a space of unfavorable interracial relations for the black children. Understanding that in a society of classes that it produces and it reproduces differences, the discussion about an included education promotes significant questions if to think the Brazilian cultural and social

\footnotetext{
1 Professora Associada do Departamento de Arte Visual da Universidade Estadual de Londrina. Londrina. Brasil. E-mail: candida.carvalho@uel.br
}

Revista Devir Educação, Lavras, vol.3, n.1, p.127-139 jan./jun., 2019. 


\section{DEVIR EDUCAÇÃO \\ ISSN: 2526-849X}

formation, as well as the education structure that can create and recreate relations of discrimination and of prejudice. In this form, a critical glance is necessary to reveal the form as the permeated practices of prejudice and prewitty thought they are built in the school space, since the school is an institution constantly challenged by practices that they produce and reproduce the social conflicts, showing up prejudices, domination, alienation, intolerâncias and racismos. To break this cycle it is necessary, according to Horkheimer and Adorno (1985), to release the men, of the darkness of the ignorance and to make possible the understanding of the society and of the culture, when there is practising critical pedagogic practice that contributes to the social transformation, the explanation and the emancipation.

Keywords: Education; Prejudice; Violence

\section{Introdução}

Discutir a relação entre o preconceito racial e a educação a partir de estudos sobre o preconceito racial na escola, procurando identificar os elementos intrínsecos ao preconceito, presentes nas relações sociais e nas instituições educativas e como eles se constituem na atualidade é uma necessidade premente. Este texto se baseia nos estudos teóricos sobre o preconceito desenvolvidos no Projeto de Pesquisa "Semiformação e educação no Contexto da Sociedade Danificada: para além do território demarcado", desenvolvido por docentes da Universidade Estadual de Londrina e usa a Teoria Crítica para sustentar discussão de questões educacionais atuais, em especial, Theodor Adorno e Max Horkheimer, buscando conforme o que os autores apontam, o desvelamento das condições que propiciam e difundem o preconceito, procurando no potencial emancipatório presente na própria educação, uma educação inclusiva, uma “educação para a autonomia”.

As investigações feitas sobre o papel e as características totalitárias existentes na população foram difundidas na obra "A Personalidade Autoritária", de Adorno (1950), em que os autores, tendo como foco a ligação entre ideologia política e características psíquicas, apresentam características de indivíduos predispostos ao preconceito. Segundo Horkheimer e Adorno (1978), o tipo totalitário apresenta uma estrutura rígida, de pessoas seriamente limitadas no estabelecimento de relações espontâneas:

trata-se indivíduos com profundas lesões psíquicas (...). Em geral, perderam em grande parte a capacidade de realizar experiências vivenciais e, para modificá-los seriamente (...) seria necessário, em primeiro lugar formar ou reconstruir nesses indivíduos, mediante processos demorados e fatigantes, a capacidade de estabelecer relações espontâneas e vitais com os homens e as coisas $(1978$, p.180). 


\section{QO DEVIR EDUCAÇÃO \\ ISSN: 2526-849X}

Estas pessoas não conseguem estabelecer relações com os outros e projetam sentimentos de desprezo, cinismo e intolerância sobre o objeto de preconceito, como mecanismo de defesa a qualquer forma de sofrimento. Ao não admitir os próprios impulsos e projetá-los sobre a vítima em potencial são cometidas duas atrocidades: transforma-se a vítima em perseguidor, que força o agressor a legítima defesa, e extingue-se o sujeito, transformando-o em coisa, passível de perseguições, o que segundo Horkheimer e Adorno (1985) pode ser entendido como: "quem é escolhido para inimigo é percebido como inimigo" (p. 175).

Horkheimer e Adorno (1978), continuam a descrição das características do tipo totalitário enfatizando uma estrutura relativamente rígida e constante e a vinculação com:

a autoridade - o reconhecimento cego, obstinado e intimamente rebelde tributado a tudo o que se reveste de poder. Temos, depois, a enfatização dos valores convencionais do momento, como a conduta exterior correta, o êxito, a diligência e capacidade no trabalho, a higiene física, a saúde conformista e não-crítica. (1978, p. 178)

Horkheimer e Adorno (1985), defendem a tese de que o preconceito não se relaciona imediatamente com o seu alvo, pois é mediado por necessidades psíquicas e sociais que revelam uma fragilidade do indivíduo frente as condições que o mundo apresenta.

Crochik (1997), em consonância com Horkheimer e Adorno, confirma o fato de o preconceito resultar de conflitos sociais e individuais.

No conflito social, manifesto na esfera da cultura, entre a luta contra a natureza necessária para a auto conservação e a regulamentação para o convívio social; no conflito individual, entre os desejos do indivíduo e a possibilidade de sua realização. (1997, p.44).

Os autores esclarecem que a luta eficaz contra os movimentos totalitários e o pensamento regressivo, para atingir as raízes do totalitarismo não é possível sem o conhecimento das suas causas. Nesse sentido, para explicarmos melhor como as relações sociais delineiam a incapacidade humana de reflexão e tomada de decisões autônomas, vamos no voltar para a obra de Horkheimer e Adorno "Dialética do esclarecimento" em que os autores explicam o desenvolvimento da civilização ocidental, o processo pelo qual o homem vence as trevas da ignorância, do preconceito e da submissão, mas 


\section{OO DEVIR EDUCAÇÃO \\ ISSN: 2526-849X}

contudo, acreditamos ter reconhecido com a mesma clareza que o próprio conceito desse pensamento, tanto quanto as formas históricas concretas, as instituições da sociedade com as quais está entrelaçado, contém o germe para a regressão que hoje tem lugar por toda parte. Se o esclarecimento não acolhe dentro de si a reflexão sobre esse elemento regressivo, ele está selando seu próprio destino. Abandonando a seus inimigos a reflexão sobre o elemento destrutivo do progresso, o pensamento cegamente pragmatizado perde seu caráter superador e, por isso, também sua relação com a verdade. (HORKHEIMER\&ADORNO, 1985, p.13).

Dessa forma entendemos como o pensar tornou-se automático e reificado e o esclarecimento com todo o potencial libertador sucumbe, ante a isenção de reflexão e o domínio cego e autoritário da razão técnica impedindo uma formação esclarecida e emancipatória.

Os autores explicitam a ligação entre o esclarecimento, o progresso e a barbárie, e demonstram que na medida em que o progresso não acolhe em si a reflexão crítica sobre si mesmo, acaba desencadeando a barbárie e a regressão. Horkheimer e Adorno ao refletir sobre a ambiguidade contida no conceito de progresso, inferem que o mesmo contém barreiras de exclusão e que os homens perderam o componente humano presente na cultura.

Podemos argumentar que Adorno e Horkheimer ao assumirem a contradição do conceito de progresso, nos conclamam a pensar no confronto crítico necessário com a sociedade real, pois, a luta para a resolução dos problemas enfrentados pelo homem no percurso da história, tem sido cada vez mais compreendido como fim em si mesmo, na busca pela dominação da natureza, em detrimento do próprio homem.

Na mesma linha de pensamento dos autores frankfurtianos, Richard Rubenstein, citado por Bauman (1998), escreve sobre o "avanço da civilização". O poderio científico e tecnológico da nossa civilização galgou novas altitudes com a "solução final", imposta aos judeus, ao assumir "com êxito" uma tarefa sem precedentes. O autor explica que nessa tarefa nossa sociedade revelou-nos uma capacidade até então insuspeitada...

O mundo dos campos da morte e a sociedade que engendra revelam o lado mais obscuro da civilização judaico-cristã. Civilização significa escravidão, guerras, exploração e campos da morte. Também significa higiene médica, elevadas ideias religiosas, belas artes e requintada música. É um erro imaginar que civilização e crueldade selvagem sejam antíteses... Em nosso tempo as crueldades, como muitos outros aspectos do nosso mundo, passaram a ser administradas, de maneira muito mais efetiva que em qualquer época anterior...(...) tanto a criação como a destruição são aspectos inseparáveis do que chamamos civilização (1998, p 28). 


\section{QO DEVIR EDUCAÇÃO \\ ISSN: 2526-849X}

Na exaltação do progresso material da nossa civilização, subestimamos seu potencial destruidor que culminou na mais violenta forma de preconceito, o racismo anti-semita. $\mathrm{O}$ genocídio, ou o extermínio em massa dos judeus, foi o ápice das medidas discriminatórias adotadas desde 1933 pelo governo nazista e que - permitiram a criação de leis anti-semitas, violências e perseguições, como o pogrom e a kristallnacht, noite dos cristais, instituição dos guetos, grupos de extermínio e câmaras de gás - cresceram a cada ano. Horkheimer e Adorno em "elementos do anti-semitismo; limites do esclarecimento", explicam o racionalismo irracional e o crescente processo de alienação - o processo de regressão do esclarecimento presente na cultura e o consequente retorno da civilização esclarecida à barbárie.

O que nos preocupa é que nenhuma das condições que tornaram Auschwitz possível desapareceu.

\section{Preconceito: a face obscura}

Não podemos negar que o holocausto dos judeus na Alemanha nazista e a escravidão negra determinou grande parte da produção acadêmica voltada para o estudo do racismo no século XX.

Horkheimer e Adorno (1985), discorrem sobre o irracionalismo do anti-semitismo em que os judeus são estigmatizados como o mal absoluto, pois:

Aos trabalhadores, que afinal são os visados, ninguém o diz na cara (e com razão); os negros, é preciso conservá-los em seu lugar; mas quanto aos judeus, a terra precisa ser purificada deles, e o grito que conclama a exterminá-los como insetos encontra eco no coração de todos os fascistas em potencial de todos os países. (1985, p. 157).

Para o entendimento do preconceito e da dominação vamos nos voltar para a escravidão negra no Brasil. A sociedade brasileira caracteriza-se pela pluralidade cultural, produto de um processo histórico que colocou no mesmo contexto histórico grupos étnicos diferentes, os portugueses, os índios e os negros de origem africana. Esse contato evidenciou as diferenças raciais que se traduziram em desigualdade de direitos e papéis sociais, no qual o branco quase sempre representou o papel de comando enquanto o negro e o índio representavam o de subordinado, levando segundo Cândido (2002) à construção de um país inegavelmente miscigenado, multifacetado, marcado pelo antagonismo e imprevisibilidade. 


\section{QO DEVIR EDUCAÇÃO}

ISSN: 2526-849X

A história colonial mostrava relações assimétricas de poder entre os povos, uma hierarquia de classes que evidenciava relações desiguais entre colonizadores e colonizados, tendo como centro a raça branca e a cultura europeia, que dominaram e subjugaram o índio e o negro. A identidade cultural brasileira foi forjada nestes embates. A propalada democracia racial, que divulga a cultura brasileira como homogênea em relação às questões raciais, encobriu os embates ocorridos e as tensões presentes na convivência intercultural desta sociedade. Essa relação de desigualdade e preconceito, foi reforçada pela política eugênica defendida pelo conde Gabineau, no "Ensaio sobre a desigualdade das raças humanas" (Leiris, 1984), que queria defender a aristocracia europeia ameaçada pela democracia, e por isso, apresentou os aristocratas como uma raça superior, que denominou de "ariana", à qual atribuiu missão civilizadora $(1984$, p.5).

A expressão "discriminação racial", supõe uma diversidade onde o "outro", o estranho, é geralmente visto como um ser diferente, seja devido a sua posição social, sexo, características físicas, entre outros.

Ao não enxergar o "outro" como "ser humano" são cometidas duas barbaridades. Tirase a "identidade do outro", despojando-o de sua humanidade, também são projetadas sobre o "outro" características falsas, errôneas, que sendo desejáveis, são abominadas e passíveis de discriminação. Essa discriminação ao extremo leva a eliminação desse "não ser".

A luta contra o racismo é indispensável se quisermos construir um futuro em que o ser humano valorize a diversidade, a diferenciação e a constante multiplicação do diferente - do outro - como essencial à vida. A humanidade não tem outra opção.

Horkheimer e Adorno (1985) definem o conceito de raça na perspectiva do antisemitismo", e nos permitem refletir sobre a universalidade desse termo:

A raça não é imediatamente, como querem os racistas, uma característica natural particular. Ela é, antes, a redução ao natural, à pura violência, a particularidade obstinada que, no existente, a particularidade obstinada que, no existente, é justamente o universal. (1985, p. 158).

Percebe-se que o racismo, isto é, a pretensa superioridade racial, fundamentada na pretensa pureza biológica, é também ideológica servindo para a dominação e expropriação. Faz parte, também de um "mecanismo" mais geral, que o engloba como um caso particular.

Wedderburn (2007) ao analisar o surgimento do racismo, identificou três dinâmicas convergentes de um mesmo processo:

Revista Devir Educação, Lavras, vol.3, n.1, p.127-139 jan./jun., 2019. 


\section{QO DEVIR EDUCAÇÃO \\ ISSN: 2526-849X}

a) a fenotipização de diferenças civilizatórias e culturais; b) a simbologização da ordem fenotipizada através da transferência do conflito concreto para a esfera fantasmático (isso implica fenômenos como a demonização das características fenotípicas do vencido em detrimento da exaltação das características do segmento populacional vencedor); c) a ereção de uma hierarquização raciológica da ordem social, mediante a subordinação política e socioeconômica permanente do mundo populacional conquistado. (2007, p. 182.

$\mathrm{O}$ autor esclarece que inter-relacionamento entre esses três elementos diferentes são determinantes para a gênese e expansão do racismo, e o mesmo dificilmente poderia existir sem essas bases sustentadoras.

Em relação ao preconceito racial Blumer (1939) faz questão de esclarecer que são quatro os sentimentos que estão sempre presentes no preconceito racial do grupo dominante: a - de superioridade; b - de que a raça subordinada é intrinsecamente diferente e alienígena; c de monopólio sobre certas vantagens e privilégios; d - de medo ou suspeita de que a raça subordinada deseje partilhar as prerrogativas da raça dominante.

Nogueira (1989), ao continuar seus estudos sobre o racismo, compara o racimo no Brasil e em Portugal. Para o autor, em Portugal foi verificada uma forma de preconceito relacionada à origem religiosa, dessa forma o "cristão-novo", judeu recém convertido ao cristianismo e o muçulmano sofreriam preconceito de origem. Dessa forma seriam rotulados devido à sua origem social, religiosa e cultural, o que dificultaria o acesso a títulos de nobreza e outras posições socialmente relevantes.

Os diferentes tipos de intolerância no Brasil, são atribuídas também, ao processo de colonização e miscigenação.

No Brasil, o processo de miscigenação, o ideal do branqueamento, produziu uma ideologia do branqueamento, fundamentando um preconceito escondido, velado, sutil como bem explicitou Nogueira (1985) em "Preconceito Racial de Marca e Preconceito Racial de Origem". A miscigenação, decorrente do processo de dominação e abuso sexual, geralmente do sexo feminino, apresenta uma função reguladora, pois "é através dela que emergem permanentemente, e por cooptação racial, os novos setores de populações fenotipicamente diferenciados, que tenderão naturalmente a reforçar os dispositivos de dominação do segmento minoritário dominador.” (WEDDERBURN, 2007, p. 186).

Segundo Hasenbalg (1979) o racismo após o fim da escravidão implicou no desajustamento psicológico, cultural, social e econômico de um grupo historicamente 


\section{QO DEVIR EDUCAÇÃO \\ ISSN: 2526-849X}

oprimido. Ou seja, a Lei Áurea, acabou formalmente com o processo exploratório que por mais de 330 anos imperou no Brasil, mas não foi acompanhada por outras leis que contribuíssem para diminuir o abismo social existente antes do fim da escravidão e não tiveram "nenhuma preocupação com a integração sócio-econômica das vítimas diretas ou indiretas do cativeiro, os negros e seus descendentes." (FERNANDES, 1971, p. 126).

O fim da escravidão não foi acompanhado por benefícios à população escravizada, pelo contrário, os privilégios das classes "superiores" continuaram e a inexistência de políticas e leis sociais no Brasil capazes de inserir na lógica da dinâmica econômica, educacional e social brasileira, os escravos libertos, minou os direitos democráticos do negro, solidificando uma hierarquia de grupos sociais antagônicos.

Entendendo que numa sociedade de classes que produz e reproduz diferenças, o debate acerca de uma educação inclusiva fomenta questões significativas para se pensar a formação cultural e social brasileira, assim como a estrutura educacional que pode criar e recriar relações de discriminação e de preconceito. Dessa forma, é necessário um olhar e reflexão crítica para desvelar a forma como as práticas permeadas de preconceito e pensamento preconceituoso são construídas no espaço escolar.

\section{A Face obscura do Preconceito na escola}

Na sociedade contemporânea continuam os debates e reflexões sobre a questão racial, e apesar de alguns pesquisadores voltarem seus estudos para desenvolver análises sobre o preconceito na sociedade e na escola, o panorama é ainda empobrecido. Estudos sobre a questão racial e a educação são importantes, pois a escola é uma instituição desafiada constantemente por práticas que produzem e reproduzem os conflitos sociais, evidenciando preconceitos, dominação, alienação, intolerâncias e racismos.

O presente texto derivou do Projeto de Pesquisa "Semiformação e Educação no Contexto da Sociedade Danificada: para além do território demarcado", desenvolvido por docentes da Universidade Estadual de Londrina que tem por objetivo compreender acerca do processo (semi) formativo docente na educação no contexto da sociedade danificada à luz dos fundamentos da teoria crítica da sociedade. O estudo se justifica, pela necessidade de pensar criticamente a educação e a formação humana dos profissionais, ao longo, tanto, da formação inicial quanto da continuada, buscando novos horizontes pedagógicos em favor de um trabalho formativo envolvido e direcionado pela tomada de consciência e autocrítica docente. 


\section{QO DEVIR EDUCAÇÃO \\ ISSN: 2526-849X}

Nogueira (1985), faz uma diferenciação comparativa, pelo viés sociocultural, do preconceito no Brasil e nos EUA. De forma resumida, o preconceito racial no Brasil, segundo o autor é o preconceito de marca pois opera em relação a diferenciações fenótipas, isto é, quando toma por pretexto para as suas manifestações os traços físicos do indivíduo, a fisionomia, a cor da pele, os cabelos, olhos, forma dos lábios e nariz, entre outros, e nos Estados Unidos o preconceito racial é de origem, decorrente de diferenciações genótipas, pois basta a suposição de que o indivíduo descende de certo grupo étnico para que sofra as consequências do preconceito.

Ao explicitar a diferença entre preconceito de marca e de origem, o autor esclarece que ambos são marcados por traços raciais, colocando a diferença no ajustamento dos indivíduos, se a luta pela ascensão social e solução de problemas é individual, o preconceito é o de marca se, ao contrário, os dois grupos raciais, discriminador e discriminado se hostilizam reciprocamente, é caracterizado o preconceito de origem.

Dessa forma inferimos que o racismo no Brasil é motivado por traços raciais, por um padrão estético social relacionado a brancura, que pretere a cor negra, pois "a cor da pele parece constituir o obstáculo, a anormalidade a sanar.” (RAMOS, 1957, p.150).

Mesmo o Brasil sendo um país miscigenado, é marcado pelo antagonismo e tensões que se refletem na escola. Segundo Cavalleiro (2005), as práticas da escola estão permeadas pelas lógicas sociais e raciais em que os envolvidos no processo de escolarização professores, diretores, e demais funcionários - desenvolvem um pensamento marcado pela estrutura racial da sociedade em que vivemos, na qual a existência do racismo é negada e o mito da democracia racial ainda está fortemente presente.

A desigualdade e opressão social reproduzem-se na escola apresentando-se de modo a inferiorizar a população negra, contribuindo para a perpetuação de estereótipos. Alexandre (2009), ao analisar o desempenho escolar das crianças negras, identifica que a avaliação, o conteúdo, o livro didático, a metodologia, o currículo e a prática pedagógica, têm contribuído negativamente para o desempenho escolar das crianças, gerando um autoconceito negativo, atrasando ou mesmo impedindo o crescimento intelectual das crianças negras.

Reforçando o dito anteriormente Cavalleiro (2005) explica que os materiais didáticopedagógicos trabalhados nas salas de aula apresentam apenas pessoas brancas como referência positiva e que "quase sem exceção, os negros aparecem nesses materiais apenas para ilustrar o período escravista do Brasil Colônia ou, então, para ilustrar situações de subserviência ou de desprestígio social.” (2005, p.13).

Revista Devir Educação, Lavras, vol.3, n.1, p.127-139 jan./jun., 2019. 


\title{
00 DEVIR EDUCAÇÃO
}

ISSN: 2526-849X

Ao não valorizar a história do povo negro a escola continua a reforçar referenciais de submissão e servilismo perpetuando e incutindo nas crianças negras sentimentos de inferioridade, expondo as crianças, muitas vezes, a brincadeiras e ofensas consideradas inofensivas.

Ianni (2004) ao se referir sobre a dialética das relações raciais, nas quais se inserem as relações raciais explica que:

\begin{abstract}
São várias, mutáveis e contraditórias as determinações que constituem o indivíduo, no singular e coletivamente, o que pode transformá-lo e transformá-los; daí constituindo-se o "negro", o "branco", o "árabe", o "judeu", o "hindu", o "mexicano", o "paraguaio", o "senegalês", o "angolano", .... todos e cada um visto como criados e recriados, modificados e transfigurados na trama das relações sociais das formas de sociabilidade e dos jogos das forças sociais; envolvendo sempre processos socioculturais e político-econômicos, desdobrando-se em teorias, doutrinas e ideologias. Assim se dá a metamorfose do indivíduo "em geral", indeterminado, em indivíduo "em particular", determinado, concretizado por várias, distintas e contraditórias determinações. Esse o clima em que germina o "eu" e o "outro", o "nós" e o "eles", compreendendo identidade e alteridade, diversidade e desigualdade, cooperação e hierarquização, divisão do trabalho social e alienação, lutas sociais e emancipação. (2004, p. 27).
\end{abstract}

O autor argumenta que essa é uma característica da sociedade moderna capitalista que fabrica a "questão racial", assim como "as desigualdades masculino-feminino, o contraponto natureza e sociedade e as contradições de classes sociais", além de outros problemas com implicações práticas e teóricas. São enigmas que nascem e se desenvolvem com a modernidade, por dentro e por fora do "desencantamento do mundo". (IANNI, 2004, p 28).

\section{Considerações Finais}

A escola, em relação as questões raciais, apresenta ambiguidades, pois, de um lado é vista como um caminho no processo de mobilidade social, e por outro é espaço de relações inter-raciais desfavoráveis para as crianças negras. A esse respeito Pinto (1993) se manifesta:

chegar a um sentimento comum de pertencimento ao mesmo passado histórico e cultural.

Ao que tudo indica, a escola, que poderia e deveria contribuir para modificar as mentalidades antidiscriminatórias ou pelo menos para inibir as ações discriminatórias, acaba contribuindo para a perpetuação das discriminações, 


\section{QO DEVIR EDUCAÇÃO \\ ISSN: 2526-849X}

seja por atuação direta de seus agentes, seja por sua omissão perante os conteúdos didáticos que veicula, ou pelo que ocorre no dia-a-dia da sala de aula" (1993, p.27).

As omissões e os silêncios, por parte do sistema e da comunidade escolar e as "brincadeiras" são formas veladas de perpetuação do racismo entre os brancos e eficazes ao incutir nas crianças negras marcas de uma violência que as inferioriza.

Na obra "Do silêncio do lar ao silêncio escolar: racismo e preconceito e discriminação na educação infantil", Cavalleiro (2003) ao pesquisar crianças com identidades negativas em relação ao seu grupo étnico, objetivou verificar os silêncios do professor, o silêncio da criança e o silencio da família, ante situações discriminatórias. Em relação ao ambiente escolar, a autora constatou que as professoras trabalham os conflitos étnicos, situações e problemas de agressões ou relacionamento entre os alunos na escola, pela via do auto respeito, mas que diferenças étnicas não são refletidas por ignorarem nas próprias ações e nas dos estudantes, o preconceito.

Não percebem a influência do material didático-pedagógico na construção da identidade da criança e desconsideram os rótulos, apelidos referentes a cor da pele, e atitudes de desprezo, que expõe as crianças a um ritual de inferiorização gerando impotência, dor e silêncio.

As crianças são expostas, dessa forma, a experiências excludentes e humilhantes, e as professoras que deveriam trabalhar de forma esclarecedora o preconceito e o racismo, silenciam, e se isentam da responsabilidade, culpando a família.

Para romper esse "ciclo" é necessário que os professores reconheçam a presença do preconceito, da violência e do bullying na escola e valorizem positivamente a criança negra no cotidiano escolar, mas, para isso, precisam identificar como as ideologias se constituem, para romper, ao invés de continuar, as formas existentes de dominação social e cultural. Nesse aspecto é preciso a conscientização de que as escolas, por muitos anos, contínua e sistematicamente ensinaram conceitos que contribuíram para a manutenção do racismo. Textos racistas e a ausência de professores representando as minorias étnicas comprovavam a pretensa superioridade de um grupo hegemônico.

A escola necessita, com urgência, segundo Horkheimer e Adorno (1985), livrar os homens, das trevas da ignorância e possibilitar a compreensão da sociedade e da cultura, exercendo prática pedagógica crítica que contribua para a transformação social, o esclarecimento e a emancipação. 


\section{Q DEVIR EDUCAÇÃO \\ ISSN: 2526-849X}

\section{Referências}

ADORNO, T.W. et all. The Authoritarian Personality. Nova York, Harper, 1950.

ALEXANDRE, I.J. Relações raciais: um estudo com alunos, pais e professores. Cuiabá: UFMT, 2009.

BAUMAN, Z. Modernidade e holocausto. Rio de Janeiro: Jorge Zahar, 1998.

BLUMER, H. The nature of racial prejudice. Social Process in Hawai. Honolulu, v 5, 1939.

CAVALLEIRO, E.S. Introdução. In: Educação anti-racista caminhos abertos pela Lei 10.639/03. Brasília, SECAD, 2005.

CROCHIK. J.L. Preconceito: indivíduo e cultura. São Paulo: Robe, 1997.

FERNANDES, F. In: BASTIDE, R. \& FERNANDES, F. Brancos e negros em São Paulo. São Paulo: Anhembi, 1971.

HASENBALG, C.A. Discriminação e desigualdades raciais no Brasil. Rio de Janeiro: Graal, 1979.

IANNI, O. Dialética das relações raciais. Estudos Avançados. V. 18 n 50, São Paulo: Jan/Apr 2004.

HORKHEIMER, M. \& ADORNO, T.W. Dialética do Esclarecimento. Rio de Janeiro: Jorge Zahar Editor, 1985.

HORKHEIMER, M. \& ADORNO, T.W. Preconceito. In: Temas Básicos da Sociologia. São Paulo: Cultrix, 1978.

LEIRIS, M. Origem e evolução dos dogmas da desigualdade de homens e raças. Correio da Unesco. Rio de Janeiro: ano 12, n 1, jan 1984.

MELLO \& SOUZA, A.C. Racismo: crime ontológico. In: Revista Ethnos Brasil: cultura e sociedade, ano $1, \mathrm{n}^{\circ} 1$, mar 2002.

NOGUEIRA. O. O estatuto de puritate sanguinis e o racismo brasileiro. Revista do Instituto Histórico e Geográfico do Espírito Santo, Vitória, nº 39, 1989.

NOGUEIRA, O. "Preconceito racial de marca e preconceito racial de origem - sugestão de um quadro de referência para a interpretação do material sobre relações raciais no Brasil". In: QUEIROZ, T.A. Tanto preto quanto branco; estudos de relações raciais. São Paulo: Edusp, 1985.

PINTO, R. P. Movimento negro e educação do negro: a ênfase na identidade. Cadernos de Pesquisa. São Paulo: Fundação Carlos Chagas/Cortez (86), ago. 1993. 


\section{OO DEVIR EDUCAÇÃO}

ISSN: 2526-849X

RAMOS, G. Introdução crítica à sociologia brasileira. Rio de Janeiro: ANDES, 1957.

WEDDERBURN, C. M. O racismo através da história: da antiguidade à modernidade. Copyright 2007 @ Carlos Moore Wedderburn. Disponível em pdf. 